[3] Arends S et al. heumatology 2015;54:1333-1335

Acknowledgements: Faculty of Health Sciences and University Institute for Gender Studies of the University of Alicante supported M. Blasco-Blasco.

Disclosure of Interest: None declared

DOI: 10.1136/annrheumdis-2017-eular.4219

\section{FRI0452 IMPACT OF A TRAINING PROGRAM AND EARLY REFERRAL ON DIAGNOSTIC DELAY IN PATIENTS WITH AXIAL SPONDYLOARTHRITIS: RESULTS FROM THE SPANISH ATLAS}

M. Garrido-Cumbrera ${ }^{1}$, D. Galvez-Ruiz ${ }^{1}$, V. Navarro-Compan ${ }^{2}$,

J. Gratacós-Masmitja ${ }^{3}$, C. Blanch Mur ${ }^{4}$, E. Collantes-Estevez ${ }^{5}$

P. Zarco-Montejo ${ }^{6}$, O. Braçe ${ }^{1} .{ }^{1}$ Universidad de Sevilla, Seville; ${ }^{2} \mathrm{H}$. la Paz, Madrid: ${ }^{3}$ H. Parc Tauli, Sabadell; ${ }^{4}$ Novartis, Barcelona: ${ }^{5}$ Universidad de Córdoba, Cordova; ${ }^{6}$ H. Fundación Alarcón, Madrid, Spain

Background: In patients with axial spondyloarthritis (axSpA), diagnosis delay (DD) postpones the initialisation of the most appropriate treatment with irreversible consequences on physical function, mobility and quality of life of patients. DD is also responsible for increased health costs resulting from incorrect referrals, visits to inappropriate health professionals and poorly planned diagnostic tests. Many initiatives have been undertaken in recent years in an attempt to reduce DD but their influence is still unknown.

Objectives: i) To determine diagnosis delay in patients with ax-SpA in Spain; ii) To assess the pre-diagnosis care process; iii) To analyse the possible beneficial effects on DD of a training programme for primary care physicians and early referral to rheumatology units.

Methods: A sample of 680 patients diagnosed with ax-SpA was interviewed during 2016 as part of the Atlas in Spain. This project aims to improve early diagnosis and to promote the use of effective treatments in ax-SpA patients. Collected data included: socio-demographics, medical visits prior to diagnosis, date for first symptoms and diagnosis and disease characteristics. This information was used to determine the DD and the possible beneficial effects on DD of a training programme for primary care physicians and early referral to rheumatology units. A descriptive analysis was performed, stratifying the results according to the start of the symptoms (before and after 2009). The ESPeranza Program (a Spanish prospective multicentre national health programme aimed at facilitating early diagnosis of patients with ax-SpA) started in 2009 .

Results: $53 \%$ of the patients included were females. Mean scores (standard deviation) were 45.7 (10.8) years for age and 12.4 (11.2) for disease duration. $77.1 \%$ were HLA-B27+. Visits to health professionals prior to diagnosis included: primary care physicians $(88.5 \%)$, orthopaedic surgeons $(71.7 \%)$, rheumatologists $(70.4 \%)$, and physiotherapists $(47.6 \%)$. The mean number of consultations prior to diagnosis was $2.6 ; 3.0 ; 2.0$ and 3.4 , respectively.

Patients stated the onset of the first ax-SpA symptoms was at mean 24.4 years of age, with diagnosis at mean 32.9 years of age, translating into a mean DD of 8.5 years. For $25 \%$ of patients DD was $>12$ years, whereas a DD of $<2$ years was found in only $25 \%$ of respondents. Mean DD for patients whose first symptoms appeared before 2009 was 9.5 years, whereas for patients whose first symptoms appeared after that date it was significantly reduced to 2.5 years.

Conclusions: The mean delay in diagnosis ax-SpA in Spain is above 8 years. Patients make a large number of visits to a variety of specialist physicians before they are diagnosed, which could point to proof of wrong referrals by primary care. However, DD has fallen drastically (to a mean 2.5 years) since the implementation of the ESPeranza Program in 2009, suggesting that training primary care physicians have substantial beneficial effects on patients with ax-SpA and the care process

Acknowledgements: This project has been supported by Novartis.

Disclosure of Interest: None declared

DOI: 10.1136/annrheumdis-2017-eular.6416

\section{FRI0453 CLINICAL AND THERAPEUTIC CHARACTERIZATION OF A} COLOMBIAN COHORT WITH SPONDYLOARTHROPATHIES

M.A. Alzate ${ }^{1}$, F. Ramirez ${ }^{2}$, F. Vargas ${ }^{2}$, D. Hernandez-Parra ${ }^{1}$,

J.C. Salazar-Uribe ${ }^{3}$, P. Ortiz-Salazar ${ }^{1}$, R. Pineda ${ }^{1}$ on behalf of Artmedica IPS, Medellin, Colombia. ${ }^{1}$ Clinical information group; ${ }^{2}$ Rheumatology division, Artmedica IPS; ${ }^{3}$ School of Statistics, Faculty of Sciences, National University of Colombia, Medellin, Colombia

Background: Spondyloarthropathies (SpAs) are a group of auto-inflammatory diseases, with overlapping symptoms, that include ankylosing spondylitis (AS), psoriatic arthritis (PsA), undifferentiated spondyloarthritis (Und SpA), enteropathic arthritis, and reactive arthritis (1).

Objectives: To characterize the disease in a large Colombian cohort with $\mathrm{SpAs}$, assessing differences in its classification, clinical manifestations, laboratory results, radiographic changes, and treatment, according to the type of SpA.

Methods: A cross-sectional study was conducted in 621 patients with $\mathrm{SpAs}$, in whom sociodemographic, clinical and therapeutic characteristics were analyzed based on the type of diagnosis. Statistical association was examined by means of Chi-square tests, Fisher's exact test, Mann-Whitney test, and logistic regression analyses. In all cases, a p value $<0.05$ was considered significant.

Results: Out of the 621 patients included, AS was observed in $54,7 \%$, PsA in
$35,7 \%$, and Und $\mathrm{SpA}$ in $9,5 \%$. AS was positively associated to male gender (OR 2.05 95\% IC 1.5-2.8), younger age at onset, axial involvement (OR 23.2 95\%IC 15.2-35.5), uveitis (OR 3.8 95\%IC 2.25-6.57), radiographic sacroilitis (OR 6.95 95\%IC 3.02-16.02), and HLA-B27 positivity (OR $2.395 \%$ IC 1.5- 3.5). PsA was associated to female gender, older age at onset, arthritis, and peripheral involvement. According to the therapeutic approach, more use of conventional DMARD therapy was found in PsA and Und SpA, while more use of biology therapy in AS

Table 1. General characteristics of patients with SpAs

\begin{tabular}{|c|c|c|c|c|c|c|c|c|c|}
\hline & \multicolumn{2}{|c|}{$\begin{array}{c}\text { All } \\
\mathrm{N}=621\end{array}$} & \multicolumn{2}{|c|}{$\begin{array}{c}\text { AS } \\
\mathrm{N}=340\end{array}$} & \multicolumn{2}{|c|}{$\begin{array}{c}\mathrm{PsA} \\
\mathrm{N}=222\end{array}$} & \multicolumn{2}{|c|}{$\begin{array}{c}\text { Und SpA } \\
\mathrm{N}=59\end{array}$} & \multirow[t]{2}{*}{$\mathrm{p}$-value } \\
\hline & $\mathrm{N}$ & $\%$ & $\mathrm{~N}$ & $\%$ & $\mathrm{~N}$ & $\%$ & $\mathrm{~N}$ & $\%$ & \\
\hline \multicolumn{10}{|l|}{ Mean (SD) } \\
\hline Age, year & \multicolumn{2}{|c|}{$49.3(12.4)$} & \multicolumn{2}{|c|}{$45.2(12.5)$} & \multicolumn{2}{|c|}{$56.7(11.8)$} & \multicolumn{2}{|c|}{$45.9(12.9)$} & $<0.0001$ \\
\hline Age at diagnostic, year & \multicolumn{2}{|c|}{$40.1(12.9)$} & \multicolumn{2}{|c|}{$33.5(12.6)$} & \multicolumn{2}{|c|}{$46.8(13.5)$} & \multicolumn{2}{|c|}{$39.9(12.5)$} & $<0.0001$ \\
\hline Male & 328 & 52.8 & 208 & 61.1 & 96 & 43.2 & 24 & 40.6 & $<0.0001$ \\
\hline ge at onset, $<45$ years & 469 & 75.5 & 291 & 85.5 & 140 & 63.1 & 38 & 64.4 & $<0.0001$ \\
\hline _ow back pain & 342 & 55.1 & 266 & 78.2 & 47 & 21.2 & 29 & 49.2 & $<0.0001$ \\
\hline rthritis & 411 & 66.2 & 152 & 44.7 & 213 & 96 & 46 & 78 & $<0.0001$ \\
\hline Enthesitis & 217 & 34.9 & 136 & 40. & 37 & 16.7 & 44 & 74.6 & 0.38 \\
\hline Dactylitis & 116 & 18.7 & 49 & 14.4 & 45 & 20.3 & 22 & 37.3 & 0.0002 \\
\hline Psoriasis & 225 & 36.2 & 3 & 0.88 & 221 & 99.6 & 1 & 1.7 & $<0.0001$ \\
\hline Uveitis & 92 & 14.8 & 75 & 22.1 & 7 & 3.2 & 10 & 16.9 & $<0.0001$ \\
\hline Eami & 108 & 17.4 & 55 & 16.2 & 47 & 21.2 & 6 & 10.2 & 0.09 \\
\hline Sacroi & $70 / 171$ & 40.9 & $62 / 116$ & 53.5 & $7 / 37$ & 18.9 & $1 / 18$ & 5.6 & $<0.0001$ \\
\hline Sacroilitis (MRI) & 203/279 & 72.8 & $182 / 212$ & 85.9 & $21 / 39$ & 53.9 & $0 / 28$ & 0.0 & $<0.0001$ \\
\hline HLA-B27 & $284 / 438$ & 64.8 & $229 / 321$ & 71.3 & $17 / 61$ & 27.9 & $38 / 56$ & 67.9 & $<0.0001$ \\
\hline Axial & 397 & 63.9 & 328 & 96.5 & 37 & 16.8 & 32 & 54.2 & $<0.0001$ \\
\hline Peripheral & 488 & 78.6 & 213 & 62.6 & 218 & 98.2 & 57 & 96.6 & $<0.0001$ \\
\hline Both & 264 & 42.5 & 201 & 59.1 & 33 & 14.9 & 30 & 50.9 & $<0.0001$ \\
\hline
\end{tabular}

$\mathrm{SD}$, standard deviation; Rx, radiography; MRI, Magnetic resonance.

Conclusions: To our knowledge, this is the larger existing cohort with SpAs in Colombia. Understanding the natural history of disease is important to do an early diagnosis and treatment that could prevent irreversible disability.

References:

[1] Ehrenfeld M. Spondyloarthropathies. Best Pract Res Clin Rheumatol. 2012;26(1):135-45

Acknowledgements: None.

Disclosure of Interest: None declared

DOI: 10.1136/annrheumdis-2017-eular.4906

\section{FRI0454 M-SASSS AND CERVICAL SEGMENT C7-D1. SHOULD THE ORIGINAL SCORE BE MODIFIED?}

M.J. Moreno-Martinez ${ }^{1}$, M.J. Moreno-Ramos ${ }^{2}$, L.F. Linares-Ferrando ${ }^{2}$ ${ }^{1}$ Rheumatology, H. Rafael Mendez; ${ }^{2}$ Rheumatology, H. U.Virgen de la Arrixaca, MURCIA, Spain

Background: Ankylosing Spondylitis is characterized by axial involvement. $\mathrm{m}$ SASSS is the radiographic score that is used to evaluate the radiographic progression of the disease. It evaluates different lesions in the lumbar segment and in the cervical segment (from C2-C3 to C7-D1), both with a lateral X-ray.

Theoretically, the C7-D1 intervertebral segment should not be evaluated through a simple lateral radiograph, but with $x$-rays in special positions

Objectives: To evaluate the importance of the assessment of the C7-D1 intervertebral segment in patients with Ankylosing Spondylitis.

Methods: The patients come from a Spondyloarthritis Unit (Hospital Virgen of the Arrixaca, Murcia, Spain). All patients are diagnosed with Ankylosing Spondylitis (New York Modified Criteria)

The usual radiographic study was performed to calculate the m-SASSS (lateral cervical and lateral lumbar). We value the alterations found at level C7-D1 of patients and controls.

We compared the alterations found in patients with ankylosing spondylitis with control patients. These came from different rheumatology units, had no inflammatory pathology and had two lateral radiographs at different time periods. We collected demographic data (both from patients and from controls) and from clinical patients (analytical, activity and metrology).

Results: We included 47 patients $(81 \%$ male and $19 \%$ female) with a mean age of $48( \pm 8)$ years and a mean duration of symptoms of $18( \pm 8.5)$ years. The mean time between the two radiographic studies was $3( \pm 1.5)$ years. The control group was made up of 61 people $(40,7 \%$ men) with a mean age of 50 years $( \pm 11)$. The mean age of the control group was higher than patients $(p=0.001)$.

The C6-C7 intervertebral level could be assessed radiographically with the lateral cervical radiograph in $93,2 \%$ of the patients and in $85,2 \%$ of controls, and the C7-D1 level was only assessed in $22,7 \%$ of the patients and $50 \%$ of the controls. We analyzed whether the assessment of intervertebral level C7-D1 could be influenced by other variables such as sex, age or duration from the symptoms without finding a statistical result.

The $88,5 \%$ of patients had a lower border of $\mathrm{C} 7$ normal or with squaring, erosion or sclerosis. Only 1 patient had syndesmophyte and 2 patients had a bridge between vertebrae. On the upper border of D1, 85, $5 \%$ of patients had normal or type-1 lesions (squarin, sclerosis or erosion), there wasn't syndesmophytes and 2 patients had a bridge (Table) 